Syntax Literate: Jurnal Ilmiah Indonesia p-ISSN: 2541-0849

e-ISSN: 2548-1398

Vol. 5, No. 10, Oktober 2020

\title{
EFEKTIVITAS PEMBERIAN TERAPI DINGIN TERHADAP NYERI PASIEN ORTOPEDI: LITERATURE REVIEW
}

\section{Suci Artanti dan Sapto Haryatmo}

Akademi Keperawatan (AKPER) Ngesti Waluyo Jawa Tengah, Indonesia

Email: tanty_art@yahoo.com dan haryatsa@gmail.com

\section{Abstract}

Pain is the most common trauma in patients with mukuloskeletal disorders as a result of inflammatory reactions due to injury/trauma, infection or surgery. One of the non-pharmacological forces that can be used for pain on orthopedic mornings again is the abbreviated cold district. This study is to review the effectiveness of cold hearts against orthopedic bus pain, the pathophysiology of cold compress identified roots, and review the associated risks associated with cold. Which way to review which literature. Literature searches using PubMed, Cochrane Library, Google Scholar, with keywords: "cold indication", "cold compress", "orthopedic patient pain", "cold terapy", "cold compress", "orthopedic patient pain". 56 selected articles and 10 relevant articles. Cold therapy proved effective at lowering pain in orthopedic patients. Cold therapy is an easy procedure to apply and safe when appropriate. The force of the tool tool is good good effect on pain but the husband's disingena. Side effects of cold therapy use need to be further researched to facilitate the preparation of safe procedures in the implementation of cold therapy administration in orthopedic patients

Keywords: Cold Therapy; Cold Compress; Orthopedic Patient Pain

\begin{abstract}
Abstrak
Penelitian ini bertujuan untuk mereview keefektifan terapi dingin terhadap nyeri pasien ortopedi, patofisilogi dibalik effektifitas kompres dingin, dan mereview potensial resiko terkait penggunaan terapi dingin. Metode yang digunakan adalah literature review. Literature dicari dengan menggunakan PubMed, Cochrane Library, Google Scholar, dengan kata kunci: "terapi dingin", "kompres dingin", "nyeri pasien ortopedi", "cold terapy", "cold compress", "pain of orthopedic patients". 56 artikel diseleksi dan didapatkan 10 artikel yang relevan. Terapi dingin terbukti efektif menurunkan nyeri pada pasien ortopedi. Terapi dingin merupakan prosedur yang mudah diaplikasikan dan aman bila dilakukan sesuai prosedur. Modifikasi penggunaan alat terapi dingin tidak memberi efek yang signifikan terhadap nyeri akan tetapi meningkatkan kenyamanan pasien.

Efek samping penggunaan terapi dingin perlu diteliti lebih lanjut untuk memudahkan penyusunan prosedur yang aman dalam implementasi pemberian terapi dingin pada pasien ortopedi.
\end{abstract}

Kata kunci: Terapi Dingin; Kompres Dingin; Nyeri Pasien Ortopedi 


\section{Pendahuluan}

Pasien ortopedi merupakan pasien dengan gangguan fungsi muskuloskeletal, yang terdiri dari gangguan fungsi tulang, otot maupun persendian. Berdasarkan survey dari WHO 2016, kasus muskuloskeletal/ortopedi memberikan beban yang cukup besar dari penyakit tidak menular lainnya. Dari tahun 1990 sampai tahun 2016 kasus muskuloskeletal meningkat $61,6 \%$. Peningkatan sejumlah $19,6 \%$ terjadi pada rentang tahun 2006-2016 (Briggs et al., 2018).

Gejala yang yang sering muncul dan dirasakan pada pasien yang mengalami gangguan ini adalah nyeri. Nyeri pada pasien ortopedi biasanya timbul karena reaksi inflamasi akibat trauma/cidera, infeksi, maupun tindakan pembedahan (Kneale \& Davis, 2011). Nyeri merupakan sensasi tidak menyenangkan yang dapat mempengaruhi kemampuan individu dalam melakukan kegiatan sehari-hari. (Potter, Perry, Hall, \& Stockert, 2009) menjelaskan bahwa nyeri dapat menyebabkan pasien menderita, kehilangan kontrol, merasa sendiri, merasa lelah dan merasa tidak berdaya. Selain itu, nyeri harus menjadi perhatian bagi perawat karena bila tidak diatasi dapat menimbulkan komplikasi termasuk didalamnya syok analfilaktik, peningkatan masa rawat inap di rumah sakit dan mempengaruhi kualitas hidup pasien (Purnamasari, 2014).

Tindakan farmakologis sering menjadi pilihan utama dalam menangani nyeri bagi pasien ortopedi, akan tetapi tindakan ini dapat menimbulkan efek samping yang merugikan bagi pasien seperti mual, muntah, gatal-gatal, depresi pernafasan gangguan psikososial termasuk mempengaruhi kualitas hidup pasien (Pan, Hou, Liang, Fei, \& Hong, 2015) (Bech et al., 2015). Terapi dingin menjadi salah satu terapi nonfarmakologis yang bisa digunakan untuk membantu mengatasi nyeri pada pasien ortopedi. Pemberian terapi dingin seperti es pada kulit sekitar area cidera dapat menyebabkan konstriksi pembuluh darah sehingga menghambat konduksi nyeri oleh serabut saraf, melambatkan aliran darahan dan menurunkan udema jaringan sehinga dapat menurunkan intensitas nyeri. Akan tetapi beberapa penelitian menunjukkan bahwa pemberian terapi dingin mempunyai efek yang merugikan pasien karena dapat mengganggu homeostasis, menyebabkan nekrosis jaringan dan thrombosis (Thacoor \& Sandiford, 2019). Artikel ini bertujuan untuk mereview keefektifan terapi dingin terhadap nyeri pasien ortopedi, patofisilogi dibalik effektifitas kompres dingin, dan mereview potensial resiko terkait penggunaan terapi dingin.

\section{Metode Penelitian}

Metode penelitian yang digunakan adalah literature review mengenai efektifitas terapi dingin terhadap nyeri pasien ortopedi. Pencarian literature dilakukan secara elektronik untuk menemukan penelitian-penelitian eksperimental terkait topik terapi dingin dan nyeri pasien ortopedi. Database dan laman yang digunakan adalah PubMed, Cochrane Library, Google Scholar, menggunakan kata kunci: "terapi dingin”, "kompres dingin", "nyeri pasien ortopedi", "cold terapy", "cold compress", "pain of orthopedic patients". Artikel yang digunakan adalah artikel dengan bahasa Inggris dan Indonesia dan full-text article. 


\section{Hasil dan Pembahasan}

\section{A. Hasil Penelitian}

Dengan menggunakan kata kunci dan pembatasan artikel di atas, jumlah artikel yang ditemukan adalah 56 artikel, namun hanya 10 yang relevan. Artikelartikel yang dieksklusi adalah artikel yang bersifat komentar, studi kualitatif dan systematic review. 6 artikel menggunakan quasy experimental study, 4 diantaranya menggunakan one group pretest and posttest design, sedangkan 2 artkel menggunakan experimental group dan control group design. Partisipasi pada penelitian ini adalah pasien dengan post knee arthroplasty, post anterior cruciate ligament reconstruction, pasien dengan fraktur, dan pasien post Open Reduction Interna Fixation (ORIF). Hasil penelusuran literature disajikan dalam Tabel 1. berikut ini.

\section{Tabel 1}

Ekstraksi Hasil Penelusuran Artikel Penelitian

\begin{tabular}{|c|c|c|c|c|c|c|c|}
\hline No & $\begin{array}{c}\text { Penulis, } \\
\text { Tahun }\end{array}$ & Judul & $\begin{array}{c}\text { Partisi } \\
\text { pan }\end{array}$ & Desain & Intervensi & $\begin{array}{c}\text { Instrum } \\
\text { en }\end{array}$ & Hasil \\
\hline 1. & $\begin{array}{l}\text { Kuyucu } \\
\text { etal } \\
(2015)\end{array}$ & $\begin{array}{l}\text { Is Cold } \\
\text { Therapy } \\
\text { Really } \\
\text { Efficient After } \\
\text { Knee } \\
\text { Arthroplasty? }\end{array}$ & $\begin{array}{l}60 \\
\text { pasien } \\
\text { yang } \\
\text { post } \\
\text { knee } \\
\text { arthro } \\
\text { plasty }\end{array}$ & $\begin{array}{l}\text { Rando } \\
\text { mized } \\
\text { Control } \\
\text { Trial } \\
\text { (RCT) }\end{array}$ & $\begin{array}{l}\text { Kelompok } \\
\text { intervensi: } 27 \\
\text { pasien mendapat } \\
\text { terapi dingin } \\
\text { dengan } \\
\text { menggunakan } \\
\text { manset es yang } \\
\text { diberikan } 2 \text { jam } \\
\text { sebelum operasi } \\
\text { dan setelah } 6 \text { jam } \\
\text { post operasi } \\
\text { dilanjutkan } \\
\text { sampai hari ke } 4 \\
\text { post operasi. } \\
\text { Terapi dingin } \\
\text { diberikan } 2 \text { jam } \\
\text { setiap hari. } \\
\text { Kelompok } \\
\text { kontrol: } 33 \text { pasien } \\
\text { tidak diberi terapi } \\
\text { dingin }\end{array}$ & $\begin{array}{l}\text { Visual } \\
\text { Analog } \\
\text { Scales } \\
\text { (VAS) }\end{array}$ & $\begin{array}{l}\text { Terapi } \\
\text { dingin } \\
\text { dengan } \\
\text { menggunak } \\
\text { an manset } \\
\text { es } \\
\text { menurunka } \\
n \quad \text { skala } \\
\text { nyeri lebih } \\
\text { besar } \\
\text { dibandingk } \\
\text { an dengan } \\
\text { pasien yang } \\
\text { tidak } \\
\text { mendapat } \\
\text { terapi } \\
\text { dingin. }\end{array}$ \\
\hline 2. & $\begin{array}{l}\text { (Bech et al } \\
2015)\end{array}$ & $\begin{array}{l}\text { Device or } \\
\text { Ice: The } \\
\text { effect of } \\
\text { Consistent } \\
\text { Cooling } \\
\text { Using a } \\
\text { Device } \\
\text { Compared } \\
\text { with } \\
\text { Intermittent } \\
\text { Cooling }\end{array}$ & $\begin{array}{l}78 \\
\text { pasien } \\
\text { post } \\
\text { knee } \\
\text { arthro } \\
\text { plasty }\end{array}$ & $\begin{array}{l}\text { Rando } \\
\text { mized } \\
\text { Control } \\
\text { Trial } \\
\text { (RCT) }\end{array}$ & $\begin{array}{l}\text { Kelompok } \\
\text { intervensi: } \quad 37 \\
\text { pasien diberi } \\
\text { terapi dingin } \\
\text { menggunakan alat } \\
\text { (Don Joy Iceman) } \\
\text { Kelompok } \\
\text { kontrol: } 34 \text { pasien } \\
\text { diberi } \\
\text { dingin terapi } \\
\text { menggunakan ice }\end{array}$ & $\begin{array}{l}\text { Numeri } \\
\text { cal } \\
\text { Pain } \\
\text { Rating } \\
\text { Scale } \\
\text { (NPRS } \\
\text { ) }\end{array}$ & $\begin{array}{l}\text { Tidak ada } \\
\text { perbedaan } \\
\text { skala nyeri } \\
\text { pasien yang } \\
\text { diberikan } \\
\text { terapi es } \\
\text { dengan } \\
\text { menggunak } \\
\text { an alat dan } \\
\text { menggunak } \\
\text { an ice bag. }\end{array}$ \\
\hline
\end{tabular}




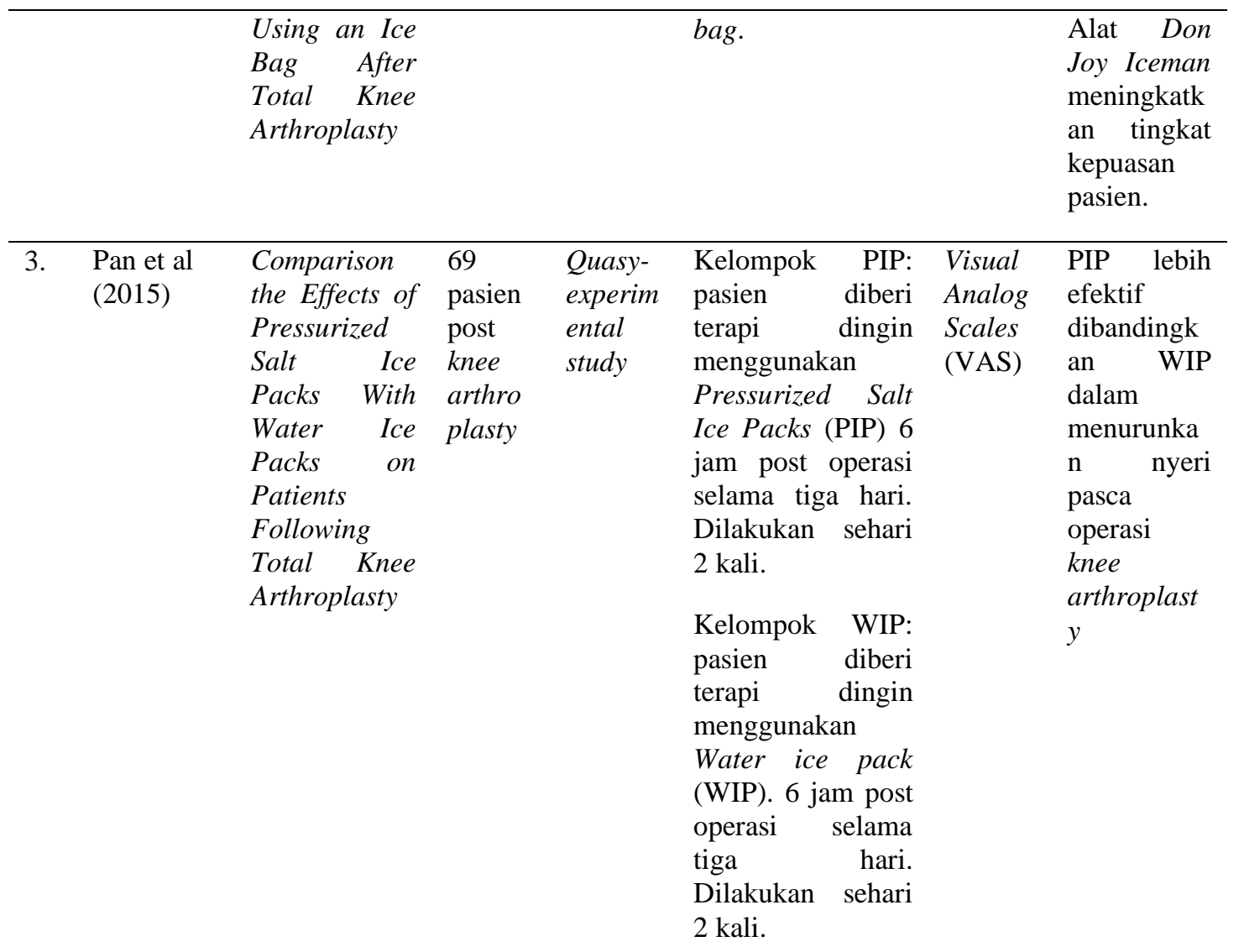

\begin{tabular}{|c|c|c|c|c|c|c|c|}
\hline 4. & $\begin{array}{l}\text { (Engelhar } \\
\text { d et al } \\
2019)\end{array}$ & $\begin{array}{l}\text { Evaluation of } \\
\text { the Effect of } \\
\text { Cooling } \\
\text { Strategies on } \\
\text { Recovery } \\
\text { After Surgical } \\
\text { Intervention }\end{array}$ & $\begin{array}{l}36 \\
\text { pasien } \\
\text { post } \\
\text { anterio } \\
r \\
\text { cruciat } \\
e \\
\text { ligame } \\
n t \\
\text { reconst } \\
\text { ruction }\end{array}$ & $\begin{array}{l}\text { Rando } \\
\text { mized } \\
\text { Control } \\
\text { Trial } \\
\text { (RCT) }\end{array}$ & 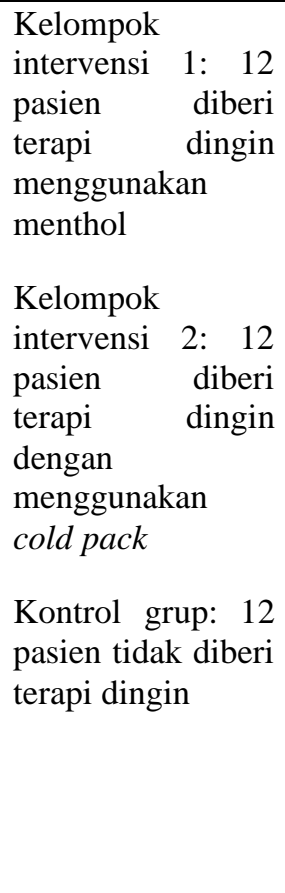 & $\begin{array}{l}\text { NRS } \\
\text { Scale }\end{array}$ & $\begin{array}{l}\text { Kelompok } \\
\text { menthol } \\
\text { menunjukk } \\
\text { an } \\
\text { penurunan } \\
\text { skala nyeri } \\
\text { lebih besar } \\
\text { dari pada } \\
\text { kelompok } \\
\text { cold pack } \\
\text { pada masa } \\
\text { rehabilitasi. } \\
\text { Tidak ada } \\
\text { perbedaan } \\
\text { penurunan } \\
\text { nyeri yang } \\
\text { signifikan } \\
\text { diantara } \\
\text { cold pack } \\
\text { group dan } \\
\text { control } \\
\text { group }\end{array}$ \\
\hline 5. & $\begin{array}{l}\text { (Sastra \& } \\
\text { Despitasar } \\
\text { i 2018) }\end{array}$ & $\begin{array}{l}\text { Pengaruh } \\
\text { Terapi Dingin } \\
\text { Cryotherapy } \\
\text { Terhadap } \\
\text { Penurunan } \\
\text { Nyeri Pada }\end{array}$ & $\begin{array}{l}12 \\
\text { Pasien } \\
\text { fraktur } \\
\text { ekstre } \\
\text { mitasT }\end{array}$ & $\begin{array}{l}\text { Quasi } \\
\text { Experi } \\
\text { mental } \\
\text { One } \\
\text { Group } \\
\text { pretest }\end{array}$ & $\begin{array}{l}12 \text { pasien dengan } \\
\text { fraktur } \\
\text { ekstremitas } \\
\text { tertutup dengan } \\
\text { diberikan } \\
\text { kompres dingin }\end{array}$ & $\begin{array}{l}\text { Numeri } \\
\text { cal } \\
\text { Rating } \\
\text { Scale }\end{array}$ & $\begin{array}{l}\text { Terapi } \\
\text { dingin } \\
\text { Cryoterapi } \\
\text { dapat } \\
\text { menurunka } \\
\mathrm{n} \quad \text { skala }\end{array}$ \\
\hline
\end{tabular}




\begin{tabular}{|c|c|c|c|c|c|c|}
\hline & $\begin{array}{l}\text { Pasien } \\
\text { Fraktur } \\
\text { Ekstremitas } \\
\text { Tertutup }\end{array}$ & ertutup & $\begin{array}{l}\text { posttest } \\
\text { design }\end{array}$ & $\begin{array}{l}\text { dengan } \\
\text { menggunakan } \\
\text { ice pack selama } \\
\text { 20-30 menit }\end{array}$ & & $\begin{array}{l}\text { nyeri pada } \\
\text { pasien } \\
\text { fraktur } \\
\text { tertutup (p } \\
\text { value } 0,00)\end{array}$ \\
\hline $\begin{array}{l}\text { Mujahidin } \\
\& \text { Utami } \\
2017\end{array}$ & $\begin{array}{l}\text { Pengaruh } \\
\text { Kombinasi } \\
\text { Kompres } \\
\text { Dingin dan } \\
\text { Relaksai } \\
\text { Nafas Falam } \\
\text { Terhadap } \\
\text { Penurunan } \\
\text { Intensitas } \\
\text { Nyeri Fraktur } \\
\text { di Wilayah } \\
\text { Kabupaten } \\
\text { Provinsi } \\
\text { Sumatra } \\
\text { Utara }\end{array}$ & $\begin{array}{l}30 \\
\text { pasien } \\
\text { dengan } \\
\text { fraktur } \\
\text { tertutu } \\
\mathrm{p}\end{array}$ & $\begin{array}{l}\text { Quasi } \\
\text { Experi } \\
\text { mental } \\
\text { One } \\
\text { Group } \\
\text { pretest } \\
\text { posttest } \\
\text { design }\end{array}$ & $\begin{array}{l}30 \text { pasien diberi } \\
\text { kompres dingin } \\
\text { dengan } \\
\text { menggunakan } \\
\text { handuk dan air } \\
\text { es. Dilakukan } \\
\text { pengukuran } \\
\text { skala nyeri } \\
\text { sebelum dan } \\
\text { sesudah } \\
\text { tindakan. }\end{array}$ & $\begin{array}{l}\text { Numeri } \\
\text { cal } \\
\text { Rating } \\
\text { Scale }\end{array}$ & $\begin{array}{l}\text { Kombinasi } \\
\text { kompres } \\
\text { dingin dan } \\
\text { relaksaksi } \\
\text { nafas dalam } \\
\text { memberika } \\
\text { n pengaruh } \\
\text { yang cukup } \\
\text { Signifikan } \\
\text { terhadap } \\
\text { penurunan } \\
\text { intensitas } \\
\text { nyeri (P= } \\
0,000)\end{array}$ \\
\hline $\begin{array}{l}\text { Manengke } \\
y \text { et al } \\
2019\end{array}$ & $\begin{array}{l}\text { Perbandingan } \\
\text { Pemberian } \\
\text { Kompres } \\
\text { Dingin dan } \\
\text { Hangat } \\
\text { Terhadap } \\
\text { Nyeri Pada } \\
\text { Pasien } \\
\text { Fraktur } \\
\text { Ekastremitas } \\
\text { Tertutup } \\
\text { Instalasi } \\
\text { Gawat } \\
\text { Darurat RS } \\
\text { Bhayangkara } \\
\text { tk III Manado }\end{array}$ & $\begin{array}{l}44 \\
\text { pasien } \\
\text { dengan } \\
\text { fraktur } \\
\text { ekstre } \\
\text { mitas }\end{array}$ & $\begin{array}{l}\text { Quasi } \\
\text { Experi } \\
\text { mental } \\
\text { One } \\
\text { Group } \\
\text { pretest } \\
\text { posttest } \\
\text { design }\end{array}$ & $\begin{array}{l}\text { Kelompok } \\
\text { kompres hangat: } \\
22 \text { pasien dengan } \\
\text { fraktur } \\
\text { ekstremitas diberi } \\
\text { kompres } \\
\text { dingin } \\
\text { Kelompok } \\
\text { kompres dingin: } \\
22 \text { pasien dengan } \\
\text { fraktur } \\
\text { ekstremitas diberi } \\
\text { kompres } \\
\text { hangat }\end{array}$ & $\begin{array}{l}\text { Numeri } \\
\text { cal } \\
\text { Rating } \\
\text { Scale }\end{array}$ & $\begin{array}{l}\text { Pemberian } \\
\text { kompres } \\
\text { dingin lebih } \\
\text { efektif dari } \\
\text { kompres } \\
\text { hangat } \\
\text { dalam } \\
\text { penanganan } \\
\text { nyeri } \\
\text { terhadap } \\
\text { pasien } \\
\text { fraktur } \\
\text { ekstremitas } \\
\text { tertutup }\end{array}$ \\
\hline $\begin{array}{l}\text { Purnamas } \\
\text { ari et al } \\
(2014)\end{array}$ & $\begin{array}{l}\text { Efektivitas } \\
\text { Kompres } \\
\text { Dingin } \\
\text { Terhadai } \\
\text { Penurunan } \\
\text { iNtensitas } \\
\text { Nyeri Pada } \\
\text { Pasien } \\
\text { Fraktur di } \\
\text { RSUD } \\
\text { Ungaran }\end{array}$ & $\begin{array}{l}21 \\
\text { pasien } \\
\text { fraktur }\end{array}$ & $\begin{array}{l}\text { Quasi } \\
\text { Experi } \\
\text { mental } \\
\text { One } \\
\text { Group } \\
\text { pretest } \\
\text { posttest } \\
\text { design }\end{array}$ & $\begin{array}{lr}21 \text { pasien diberi } \\
\text { kompres dingin. } \\
\text { Nyeri diukur } \\
\text { sebelum dan } \\
\text { sesudah tindakan. }\end{array}$ & $\begin{array}{l}\text { Numeri } \\
\text { cal } \\
\text { Rating } \\
\text { Scale }\end{array}$ & $\begin{array}{l}\text { Kompres } \\
\text { dingin } \\
\text { efektif } \\
\text { menurunka } \\
\mathrm{n} \text { nyeri ada } \\
\text { pasien } \\
\text { fraktur (p } \\
0,000)\end{array}$ \\
\hline $\begin{array}{l}\text { Kristanto } \\
\& \text { Arofiati } \\
2016\end{array}$ & $\begin{array}{l}\text { Efektivitas } \\
\text { Penggunaan } \\
\text { Cold Pack } \\
\text { Dibandingka } \\
\text { n Relaksaksi } \\
\text { Nafas Dalam } \\
\text { Untuk }\end{array}$ & $\begin{array}{l}30 \\
\text { Pasien } \\
\text { Post } \\
\text { ORIF }\end{array}$ & $\begin{array}{l}\text { Quasy } \\
\text { Experi } \\
\text { mental } \\
\text { Design } \\
\text { pretest, } \\
\text { posttest } \\
\text { with }\end{array}$ & $\begin{array}{lr}\text { Kelompok } & \\
\text { intervensi: } & 15 \\
\text { pasien } & \text { diberi } \\
\text { intervensi } & \\
\text { kompres } & \text { dingin } \\
\text { dengan } & \\
\text { menggunakan } & \end{array}$ & $\begin{array}{l}\text { Visual } \\
\text { Analog } \\
\text { Scales } \\
\text { (VAS) }\end{array}$ & $\begin{array}{l}\text { Pemberian } \\
\text { cold pack } \\
\text { memperliha } \\
\text { tkan } \\
\text { perbedaan } \\
\text { penurunan } \\
\text { skala nyeri }\end{array}$ \\
\hline
\end{tabular}




\begin{tabular}{|c|c|c|c|c|c|c|}
\hline & $\begin{array}{l}\text { Mengatasi } \\
\text { Nyeri Paska } \\
\text { Open } \\
\text { Reduction } \\
\text { Internal } \\
\text { Fixation } \\
(\text { ORIF) }\end{array}$ & & $\begin{array}{l}\text { control } \\
\text { group }\end{array}$ & $\begin{array}{l}\text { cold pack selama } \\
15 \text { menit dan } \\
\text { diulang } 4 \text { kali. } \\
\text { Kelompok } \\
\text { kontrol: } 15 \text { pasien } \\
\text { diberi intervensi } \\
\text { nafas dalam } \\
\text { selama } 15 \text { menit } \\
\text { dan diulang } \\
\text { selama } 4 \text { kali }\end{array}$ & & $\begin{array}{l}\text { sebesar } \\
4,33 \text { poin } \\
\text { dengan nilai } \\
\mathrm{T} \quad 20,55 \\
\text { dibandingk } \\
\text { an } \\
\text { pemberian } \\
\text { relaksasi } \\
\text { nafas dalam }\end{array}$ \\
\hline $\begin{array}{l}\text { Anugrah } \\
\text { et al } 2017\end{array}$ & $\begin{array}{l}\text { Pengaruh } \\
\text { Terapi } \\
\text { Kompres } \\
\text { Dingin } \\
\text { Terhadap } \\
\text { Nyeri Post } \\
\text { Operasi ORIF } \\
\text { pada Pasien } \\
\text { Fraktur }\end{array}$ & $\begin{array}{l}10 \\
\text { pasien } \\
\text { post } \\
\text { ORIF }\end{array}$ & $\begin{array}{l}\text { Experi } \\
\text { mental } \\
\text { One } \\
\text { Group } \\
\text { PreTest } \\
\text { and } \\
\text { Post } \\
\text { Test } \\
\text { Design }\end{array}$ & \begin{tabular}{l}
10 Pasien post \\
ORIF hari ke-1 \\
diberi kompres \\
dinging selama 10 \\
menit. \\
Pengukuran skala \\
nyeri dilakuakan \\
sebelum dan \\
\multicolumn{2}{l}{ sesudah kompres }
\end{tabular} & $\begin{array}{l}\text { Verbal } \\
\text { Descri } \\
\text { ptor } \\
\text { Scale }\end{array}$ & $\begin{array}{l}\text { Ada } \\
\text { pengaruh } \\
\text { yang } \\
\text { signifikan } \\
\text { dari terapi } \\
\text { kompres } \\
\text { dingin } \\
\text { terhadap } \\
\text { nyeri post } \\
\text { operasi } \\
\text { fraktur } \\
\text { ORIF }\end{array}$ \\
\hline
\end{tabular}

\section{B. Pembahasan}

1. Nyeri

Nyeri menjadi sebuah tolok ukur yang paling banyak diteliti untuk mengidentifikasi keefektivan dari terapi dingin. (Kuyucu, Bülbül, Kara, Koçyiğit, \& Erdil, 2015) mengemukakan bahwa terapi dingin menurunkan skala nyeri lebih banyak dibandingkan dengan pasien yang tidak diberi terapi dingin. Hal ini sejalan dengan penelitian yang dilakukan oleh (Sastra \& Despitasari, 2018) yang mendapatkan hasil bahwa terapi dingin dapat menurunkan skala nyeri pada pasien fraktur tertutup. Penelitian (Anugerah, Purwandari, \& Hakam, 2017) juga menunjukkan bahwa pemberian kompres dingin selama 10 menit pada pasien post ORIF hari pertama terbukti efektif menurunkan nyeri. (Kristanto \& Arofiati, 2016) mencoba membandingkan efektifitas pemberian terapi dingin dengan nafas dalam untuk menurunkan nyeri. Hasil penelitian didapat bahwa terapi dingin lebih efektif untuk menurunkan nyeri dari pada penggunaan teknik relaksaksi pada pasien ortopedi. Akan tetapi kombinasi antara terapi dingin dan teknik relaksasi memberikan hasil yang lebih efektif (Palas. R. Mujahidin \& Utami, 2017).

Pemberian terapi dingin seperti pemberian kompres es pada kulit sekitar area cidera akan mendinginkan kulit dan jaringan yang diberi kompres air dingin serta mendinginkan intra-artikular. Hal ini akan menghambat penghantaran sensasi nyeri oleh serabut saraf. Selain itu terapi dingin akan menyebabkan konstriksi pembuluh darah. Sehingga melambatkan aliran darahan dan menurunkan edema jaringan (Thacoor \& Sandiford, 2019). Hal inilah yang 
membuat terapi dingin efektif untuk menurunkan intensitas nyeri pasien ortopedi.

2. Alat terapi dingin

Pemberian terapi dingin semakin dikembangkan. Hal ini ditunjukkan dengan adanya berbagai macam alat dan metode pemberian terapi dingin. Dalam penelitian yang dilakukan (Kuyucu et al., 2015) menunjukkan bahwa penggunaan manset es terbukti efektif menurunkan nyeri dibandingkan dengan kelompok yang tidak diberi terapi dingin. Penelitian lain menunjukan tidak ada perbedaan skala nyeri pasien diberikan terapi es dengan menggunakan alat (Don Joy Iceman) dan menggunakan ice pack. Akan tetapi Don Joy Iceman meningkatkan tingkat kepuasan dan kenyamanan pasien (Bech et al., 2015).

Menurut (Pan et al., 2015) membandingkan pemberian terapi dingin dengan menggunakan Pressurized Salt Ice Packs (PIP) dan Water Ice Pack (WIP). Hasil menunjukkan bahwa PIP lebih efektif dibandingkan WIP dalam menurunkan nyeri. Hal ini terkait dengan suhu pada PIP lebih rendah dari pada suhu pada WIP. Penelitian serupa dilakukan oleh (Engelhard, Hofer, \& Annaheim, 2019) yang mencoba membandingkan pemberian terapi dingin dengan menthol dan menggunakan ice pack. Hasil menunjukkan bahwa pemberian terapi dingin dengan menthol menunjukkan penurunan skala nyeri lebih besar dari pada dengan cold pack pada masa rehabilitasi, akan tetapi perbedaan penurunan nyeri tidak terlalu signifikan.

Pemberian terapi dingin dengan menggunakan alat tidak terlalu memberi hasil yang signifikan pada penurunan nyeri pasien ortopedi, akan tetapi berpengaruh pada tingkat kenyamanan dan juga kemampuan dalam mempertahankan suhu sehingga terapi dingin akan lebih efektif.

3. Efek samping terapi dingin

Terapi dingin memiliki potensi resiko dalam penggunaannya sehubungan dengan reaksi hipotermi. (Potter et al., 2009) menjelaskan bahwa terapi dingin harus dihentikan setiap 5-10 menit. Durasi yang terlalu lama dan tekanan yang terlalu tinggi dapat membahayakan sirkulasi didaerah kulit yang tekena. Pendinginan yang berkepanjangan kurang dari 5oC dapat menyebabkan nekrosis dan trombosis. Terapi dingin efektif digunakan dalam waktu 20 menit sampai 2 jam (Thacoor \& Sandiford, 2019) (M. A.Burton \& Ludwig, 2015) menjelaskan bahwa terapi dingin tidak boleh digunakan lebih dari 20-30 menit, karena akan menyebabkan vasokontriksi pembuluh darah yang berkepanjangan sehingga sel dapat mengalami kekurangan oksigen dan nutrisi yang dapat menyebabkan kematian sel. Sedangkan (Kuyucu et al., 2015) menjelaskan jika terapi dingin merupakan terapi yang aman dan mudah diaplikasikan, tanpa menimbulkan masalah iritasi dan mengganggu penyembuhan luka. Terapi dingin aman bila dilakukan sesuai dengan prosedur. 
Suci Artanti dan Sapto Haryatmo

\section{Kesimpulan}

Terapi dingin merupakan intervensi yang efektif untuk menurunkan nyeri pada pasien dengan gangguan ortopedi baik karena trauma/cidera atau efek dari pembedahan. Terapi dingin merupakan prosedur yang mudah diaplikasikan dan aman bila dilakukan sesuai prosedur. Modifikasi penggunaan alat terapi dingin tidak memberi efek yang signifikan terhadap nyeri akan tetapi meningkatkan kenyamana pasien. Efek samping penggunaan terapi dingin perlu diteliti lebih lanjut untuk memudahkan penyusunan prosedur yang aman dalam implementasi pemberian terapi dingin pada pasien ortopedi. 


\section{BIBLIOGRAFI}

Anugerah, Amanda Putri, Purwandari, Retno \& Hakam, Mulia. (2017). Pengaruh Terapi Kompres Dingin Terhadap Nyeri Post Operasi ORIF (Open Reduction Internal Fixation) pada Pasien Fraktur di RSD Dr. H. Koesnadi Bondowoso (The Effect of Cold Compress Therapy Toward Post Operative Pain in Patients ORIF Fracture in RSD Dr. H. Pustaka Kesehatan, 5(2), 247-252.

Bech, Michelle, Moorhen, Joanne, Cho, Mary, Lavergne, M. Ruth, Stothers, Keith, \& Hoens, Alison M. (2015). Device or Ice: The Effect of Consistent Cooling Using a Device Compared with Intermittent Cooling Using an Ice Bag After Total Knee Arthroplasty. Physiotherapy Canada, 67(1), 48-55.

Briggs, Andrew M., Woolf, Anthony D., Dreinhöfer, Karsten, Homb, Nicole, Hoy, Damian G., Kopansky-Giles, Deborah, Åkesson, Kristina, \& March, Lyn. (2018). Reducing the global burden of musculoskeletal conditions. Bulletin of the World Health Organization, 96(5), 366.

Engelhard, Daniel, Hofer, Pierre, \& Annaheim, Simon. (2019). Evaluation of the effect of cooling strategies on recovery after surgical intervention. BMJ Open Sport \& Exercise Medicine, 5(1)

Kneale, Julia, \& Davis, Petter. (2011). Keperawatan ortopedik dan trauma. In Jakarta. EGC.

Kristanto, Agung, \& Arofiati, Fitri. (2016). Efektifitas Penggunaan Cold Pack dibandingkan Relaksasi Nafas Dalam untuk Mengatasi Nyeri Pasca Open Reduction Internal Fixation (ORIF). IJNP (Indonesian Journal of Nursing Practices), 1(1), 68-76.

Kuyucu, Ersin, Bülbül, Murat, Kara, Adnan, Koçyiğit, Figen, \& Erdil, Mehmet. (2015). Is Cold Therapy Really Efficient After Knee Arthroplasty? Annals of Medicine and Surgery, 4(4), 475-478.

M. A.Burton \& Ludwig, L. J. M. (2015). Fundamental of Nursing Care, Consepts, Connections, \& Skiils (2nd ed.). F. A. Davis Company.

Palas. R. Mujahidin \& Utami, S. R. N. (2017). Pengaruh Kombinasi Kompres Dingin dan Relaksai Nafas Falam Terhadap Penurunan Intensitas Nyeri Fraktur di Wilayah Kabupaten Provinsi Sumatra Utara. Jurnal Ilmiah Multi Science Kesehatan, 8, 37-49.

Pan, Liying, Hou, Dong, Liang, Wei, Fei, Jiali, \& Hong, Zongyuan. (2015). Comparison The Effects of Pressurized Salt Ice Packs with Water Ice Packs on Patients Following Total Knee Arthroplasty. International Journal of Clinical and Experimental Medicine, 8(10), 18179.

Potter, Patricia A., Perry, Anne Griffin Ed, Hall, Amy Ed, \& Stockert, Patricia A. 
Suci Artanti dan Sapto Haryatmo

(2009). Fundamentals of Nursing. Elsevier mosby.

Purnamasari, Elia. (2014). Efektifitas Kompres Dingin Terhadap Penurunan Intensitas Nyeri Pada Pasien Fraktur Di RSUD Ungaran. Karya Ilmiah.

Sastra, Lenni, \& Despitasari, Lola. (2018). Pengaruh Terapi Dingin Cryotherapy Terhadap Penurunan Nyeri Pada Fraktur Ekstremitas Tertutup. Jurnal Kesehatan Hesti Wira Sakti, 6(2), 28-36.

Thacoor, A., \& Sandiford, N. A. (2019). Cryotherapy Following Total Knee Arthroplasty: What Is The Evidence? Journal of Orthopaedic Surgery, 27(1). 